\title{
Managing medication in schools
}

\author{
R Reading
}

Arch Dis Child 2005;90:1253-1255. doi: 10.1136/adc.2005.071837

Increasing numbers of children and young people are prescribed medication to be taken in school. This article discusses general principles of prescribing medication for use in school, specific conditions for which medicines may be prescribed, and the key role of nurses in liaison with schools. Decisions about prescribing medication for use in schools do not only depend on evidence of therapeutic effectiveness but need to take into account other social and educational benefits and harms that may occur when children need to use medication in school.

\section{Correspondence to: \\ Dr R Reading, Consultant Paediatrician and Honorary Senior Lecturer in Child Health, School of Medicine, Health Policy and Practice, University of East Anglia, Norwich NR4 TTJ, UK; r.reading@uea. ac.uk}

Accepted 31 August 2005 in ncreasing numbers of children and young people are prescribed medication to be taken in school. The reasons include greater societal acceptance of drug use, therapeutic advances, rising numbers of children with complex health problems attending mainstream schools, improved liaison between healthcare professionals and schools, and increasing numbers of children with chronic conditions such as diabetes and atopy. This can pose problems for teachers, students, and parents which prescribing doctors need to consider if we are not to jeopardise the goodwill and tolerance that prevails around treatment of health problems in children. ${ }^{1}$

Recent guidance has been published by the Department for Education and Skills (DfES)Managing medicines in schools and early years settings. ${ }^{2}$ It updates previous guidance ${ }^{3}$ and is linked with the Medicines for Children and Young People document from the National Service Framework for Children, Young People, and Maternity Services. ${ }^{4}$ In this article I attempt to summarise and interpret the DfES guidance from the point of view of paediatricians who may prescribe medications to be given in school.

\section{GENERAL PRINCIPLES}

\section{Attendance at school is important}

All children have a right to education (Article 28, UN Convention on the Rights of the Child). ${ }^{5}$ Some children depend on medication in order to stay healthy enough to benefit from education. Children should not be kept from school purely because they need medicine. It is reasonable to prescribe medicines which improve the quality of life of children while they are in school.

\section{Avoid if possible}

There are few situations where medicines need to be prescribed for use in school time. Improved pharmaceutical technology has enabled many short acting drugs to be formulated in once or twice daily preparations. Emergency or as required medicines for use in school ought to only to be prescribed on the basis of good quality evidence that there will be a benefit. In balancing benefits and harms, inconvenience, stigmatisation, and exclusion from normal activities need to be weighed against therapeutic benefits. These may vary for different children with the same condition. ${ }^{6}$

\section{Teachers as healthcare providers}

Doctors are dependent on teachers and other school staff to administer medication in school. Many teachers feel they may be open to criticism at least, and damage to their career and litigation at worst, should things go wrong or they make a mistake. The DfES guidance specifically addresses these concerns, describing in detail the responsibilities of education authorities, school governing bodies, and heads in developing policies, providing insurance indemnity, and ensuring appropriate training for school staff who agree to administer medicines. As long as school staff do not act negligently and the DfES guidance is followed, they are effectively protected. Moreover, although teachers do not have to agree to giving medications, there is a duty on schools to make arrangements for children to be able to have medications.

Doctors need to reciprocate. We should be aware of teachers' concerns, however unfounded we feel them to be, and respond to them sensitively and responsibly.

\section{Legislation can help (and hinder)}

The DfES guidance includes a useful summary of the relevant legislation. The SEN and Disability Act of 2001 makes it clear that children with disabilities are entitled to attend mainstream school, that children cannot be excluded from school for medical reasons, and that many chronic medical needs can be considered a disability. This offers further legislative backup to ensure arrangements are made for children to receive essential medications in school. The 1996 Education Act obliges local health services to provide help to education authorities for children with special needs (which include those requiring medications). Health services also have an obligation to appoint a doctor for special educational needs. On the other hand, the 1968 Medicines Act requires any third party (that is, school staff) to administer medicines only out of the original container, with the prescriber's labelling and instructions. Although inconvenient, we should remember to provide two prescriptions-one for home and one for school.

\section{Care plans}

The prescribing doctor has a duty to ensure clear information and instructions are understood by 
the school, the child, and parents. The key to clear communication is the healthcare plan. In most cases the school nurse is best placed to initiate and draw this up with parents, school, doctor, and, where possible, the student. It should specify the dose, frequency, indications, and instructions for administration. Where special precautions or administration methods are required (for example, injections) it should describe the training needed and the staff approved to administer the medicine. Where relevant, it should describe what to do in an emergency. Although it is impractical to draw care plans for all children with a chronic illness, they are needed for any child who requires medicine in school. The DfES guidance includes formats of care plans which can be downloaded. ${ }^{2}$

\section{Regular review}

Care plans should be reviewed at least annually. Prescribers ought to review the prescription as well. Has it been used, is it still needed, are there alternatives? Parents, and sometimes schools, can feel threatened and vulnerable when an emergency medication is no longer prescribed, but the social and educational advantages for the child may be substantial.

\section{Training and support}

Many of the medications used in schools, as well as associated health care in children with chronic or complex medical conditions require school staff to be trained. Acute conditions such as seizures need to be recognised and distinguished from benign events such as faints. Drugs may need to be delivered in unusual ways such as via a gastrostomy. Preventive precautions may involve medications such as using inhalers before exercise. School staff may have considerable hands-on responsibilities for younger children or those with disabilities. Training for these activities includes giving information, demonstrating and assessing technical competence, and monitoring and updating of school staff. Outreach nurses, school nurses, community paediatric doctors, resuscitation officers, and other specialist healthcare trainers contribute to this rather disparate team. The strengths, weaknesses, and availability of this team need to be taken into account when prescribing medication for a child to use in school.

\section{SPECIFIC CONDITIONS \\ Asthma}

As the prevalence of asthma is around $10-15 \%$ of children, it is important that schools are aware of broad principles of management that apply to all children. Ready access to reliever inhalers is essential, yet despite widespread publicity, there are still instances where this does not happen. Schools are recommended to have a policy covering all aspects of asthma management. ${ }^{7}$ This should include recommendations for emergency treatment of severe attacks. ${ }^{8}{ }^{9}$ Individual treatment advice can be recorded on a child's asthma card. However, it is our duty to ensure schools, parents, and children and young people are familiar with all of this information.

Older children should be responsible for their own treatment. Younger children may need to have their treatment supervised or even administered by school staff, although it is good practice to encourage self management as early as practicable. Regardless of age, the school should be aware of all students who have treatment prescribed for asthma.

\section{Diabetes}

Intensive insulin regimes are increasingly the treatment method of choice, with three or four daily injections, frequent blood sugar testing, patient determined dose modifications, and in some cases continuous subcutaneous insulin infusions. While there is mounting evidence of the long term benefits of tight glycaemic control, this can be hard to reconcile with the aim of allowing normal school life and full participation in activities. Our local approach is to avoid insulin injections in school until the youngster is able to manage this themselves. If insulin injections have to be given or supervised by staff, detailed training, a school policy, an individual care plan, and written records of insulin doses prescribed and given are all necessary. Insulin pumps require the same. As with other chronic conditions requiring medication, balancing the medical benefits against the social harm is often a fine judgement.

Management of hypoglycaemic attacks is equally important. We rarely prescribe glucagon injections for school use as the anxiety, uncertainty, and scope for error engendered among non-medical school staff do not seem worth the benefits. Advice centres around administering rapidly available sugar in a safe fashion, calling for emergency help, and safely dealing with an unconscious or semiconscious child.

\section{Attention deficit hyperactivity disorder}

Methylphenidate is the standard first line medication in attention deficit hyperactivity disorder. However, the unmodified preparation has a very short half life, necessitating a midday dose. It is also a controlled drug in the UK. In view of this, schools should be responsible for administering methylphenidate in school. This may be inappropriate for older students in secondary schools. It also risks stigmatisation, or, paradoxically, undeserved kudos in some cases. Modified or sustained release preparations are now available which only require once daily dosage before school begins. They are more expensive, and the pharmacological benefits are debatable, but this should be weighed against the potential educational and social advantages of children not having to take medication in school. It is good practice to liaise with the child's school, regardless of whether or not the child is on medication.

\section{Epilepsy}

Most antiepileptic medication can be given once or twice daily and is therefore not required in school. Probably the most relevant issue is emergency medication. This only needs to be prescribed to children who have a history of prolonged seizures or status and whose school is in an area where the ambulance response is likely to be longer than 10 minutes.

Rectal diazepam has been the most commonly prescribed emergency medication, but poses particular difficulties of social acceptability, technical competence, and the need for school staff to perform intimate procedures. Paediatricians are increasingly prescribing buccal midazolam for emergency treatment of seizures; recent evidence of its safety and efficacy suggests it will become the treatment of choice. ${ }^{10}$

Whichever drug is used, a care plan with details of all aspects of emergency treatment of seizures should be drawn up and regularly reviewed. Our practice is to suggest withdrawal of emergency medication from school after one year if it has not been used. Training is still required for any staff designated to deliver the emergency medication.

Allergy
Increasing numbers of children are being supplied with
emergency treatment for anaphylactic or severe allergic
reactions. Usually these consist of adrenaline (epinephrine)
auto-injector devices, but may also include antihistamines.
There are heated arguments about the need for these drugs,
which poses difficulties in giving general advice. ${ }^{11-14}$
In my view it is inappropriate to expect non-medical school
staff to decide on the severity of an allergic attack and alter
their treatment accordingly. Schools need clear criteria about
what constitutes a severe reaction and when to treat this. 
Thus the only drug which schools should be expected to give is injected adrenaline; allowing alternatives may result in delay or avoidance of necessary emergency treatment. Others take a different view, arguing that mild and moderate allergic reactions are distressing and easily treated with oral antihistamines.

There needs to be a local agreement on policies for emergency treatment in schools and a dedicated team who provide support and training to schools. The worst possible outcome is for a school to have different recommendations for treatment of anaphylaxis in different children.

\section{THE IMPORTANCE OF NURSES}

School nurses and specialist children's community nurses are fundamental to ensuring good practice and optimum management. They are the best professionals to set up care plans, liaise between families, schools, and doctors, and maintain good lines of communication. They are often more up to date with current advances in specialist areas than doctors. They usually have a better practical understanding of how schools work and how to overcome administrative, bureaucratic, or interagency barriers. They are better at developing failsafe mechanisms for reviews and updating of care plans. They often develop close therapeutic relationships with families. They usually lead the implementation of school based healthcare policies, such as asthma plans. However, there is a shrinking pool of school and community nurses. More investment in training and employing such nurses is one part of the answer. We also need to join the debate between the nursing profession, healthcare managers, and public health practitioners about prioritising different elements of school and community nurses' work. If this is not remedied our aspirations for the management of medication in school will be jeopardised.

\section{ACKNOWLEDGEMENTS}

I am grateful to local paediatric medical and nursing colleagues, teachers, and educational staff who have collectively developed the working practices on which this paper is based. I particularly thank Debbie Upton, Gill Ward, Sally Tyler, Alison Betteridge, and Richard Beach who have helped me draft this article. I also thank David Hall and an anonymous reviewer whose comments improved the article.

Competing interests: none

\section{REFERENCES}

1 Wong ICK, Awolowo T, Gordon K, et al. Survey of administration of medicines to pupils in primary schools within the London area. Arch Dis Child 2004;89:998-1001.

2 Department for Education and Skills. Managing medicines in schools and early years settings. London: DfES, 2005.

3 Department for Education and Employment, Department of Health. Supporting pupils with medical needs: a good practice guide. London: DFEE, 1996.

4 Department of Health, Department for Education and Skills. National Service Framework for Children, Young People and Maternity Services: Medicines for children and young people. London: DoH, 2004.

5 United Nations. UN Convention on the Rights of the Child. New York, UN, 1989 (http://www.unhchr.ch/html/menu3/b/k2crc.htm; accessed 6 May 2005).

6 Williams C. Doing health, doing gender: teenagers, diabetes and asthma. Soc Sci Med 2000;50:387-96.

7 Asthma UK. School pack, (http://www.asthma.org.uk/about/ resource07.php\#6; accessed 6 May 2005).

8 British Thoracic Society and Scottish Intercollegiate Guidelines Network. British guideline on the management of asthma. Thorax 2003;58(suppl 1).

9 Reading R, Jones T, Upton C. Emergency asthma inhalers in school. Arch Dis Child 2003;88:384-6.

10 McIntyre J, Robertson S, Norris E, et al. Safety and efficacy of buccal midazolam versus rectal diazepam for emergency treatment of seizures in children: a randomised controlled trial. Lancet 2005;366:205-10.

11 Macdougall CF, Cant AJ, Colver AF. How dangerous is food allergy in childhood? The incidence of severe and fatal allergic reactions across the UK and Ireland. Arch Dis Child 2002;86:236-9.

12 Clark AT, Ewan PW. Food allergy in childhood. Arch Dis Child 2003;88:78-91.

13 Colver AF, C Macdougall C, Cant A. Food allergy in childhood. Arch Dis Child 2003;88:742-3.

14 Clark AT, Ewan PW. Food allergy in childhood. Arch Dis Child 2004;89:197.

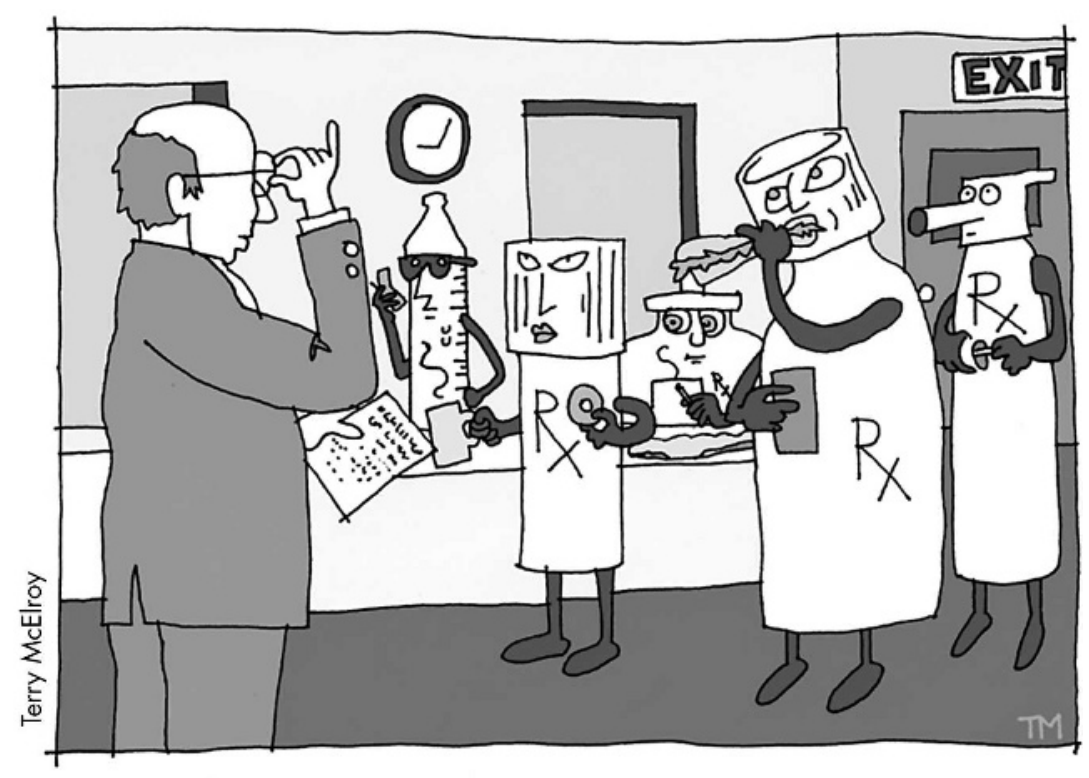

